\title{
Evaluation of high molecular weight cytokeratin (HMWCK), p27, C-X-C chemokine receptor type 4 (CXCR-4) and stromal cell-derived factor 1 (SDF-1) expressions related to tumor progression in breast cancer
}

\author{
Gonca Özgün ${ }^{1}$, Gülen Akyol${ }^{2} \odot$ \\ ${ }^{1}$ Department of Pathology, Başkent University School of Medicine, Ankara, Turkey \\ ${ }^{2}$ Department of Pathology, Gazi University School of Medicine, Ankara, Turkey
}

DOI: $10.18621 /$ eurj.423593

\begin{abstract}
Objectives: Breast cancer is the most common cancer and the most common reason for cancer death in women population. The immunohistochemical markers which could have prognostic information are always needed. Methods: This study included 365 cases of invasive ductal carcinoma (IDC), ductal carcinoma in situ (DCIS) and ductal epithelial hyperplasia. The cases divided into the following two groups according to the presence of cancer: 1) cancer group (298 cases; cases with IDC and DCIS), 2) non-cancer group (67 cases without cancer; cases with usual ductal epithelial hyperplasia [UDH] and atypical ductal epithelial hyperplasia [ADH]). All histological slides stained with high molecular weight cytokeratin (HMWCK), p27, C-X-C chemokine receptor type 4 (CXCR-4), stromal cell-derived factor 1 (SDF-1) immunohistochemically.

Results: IDC was present in 277 cases, of which 213 had pure IDC, and 64 had DCIS component adjacent to the invasive tumor. Twenty-one cases had only DCIS. Of 67 cases with epithelial hyperplasia, 31 had ADH, and 36 had UDH. Among cases with IDC, 143 had lymph node excision, of which 73 had metastasis in one or more lymph nodes, and 70 did not have metastatic disease. The expression of p27 was found to be significantly lower in the cancer group as compared to that in the non-cancer group $(p<0.0001)$. CXCR-4 expression in IDC was found to be higher than that of DCIS group. SDF-1 expression was observed to be significantly higher in cancer cases than that of non-cancer cases $(p=0.03)$.

Conclusions: The higher CXCR-4 and SDF-1 expressions are associated with tumor progression, tumor size, and lymph node status. In benign proliferative lesions, both HMWK and p27 expressions were helpful in differential diagnosis of borderline atypical ductal hyperplasia and DCIS.
\end{abstract}

Keywords: CXCR-4, SDF-1, p27, HMWCK, benign proliferative breast lesions, ductal carcinoma in situ, invasive ductal carcinoma, tissue microarray

Received: May 14, 2018; Accepted: April 30, 2019; Published Online: June 30, 2019

B reast cancer is the most common cancer type and the leading cause of cancer-related deaths in women. Invasive ductal carcinoma (IDC) constitutes the largest group of malignant breast tumors. Precursor lesions of IDC can be found around the primary tumor mass in mastectomy specimens as well as in biopsy

Address for correspondence: Gonca Özgün, MD., Başkent University School of Medicine, Department Pathology, 06490 Bahçelievler, Çankaya, Ankara, Turkey,E-mail: goncabarit@hotmail.com 
specimens obtained from patients presenting with the complaint of breast mass $[1,2]$. Precancerous lesions of the breast include usual ductal epithelial hyperplasia (UDH), atypical ductal epithelial hyperplasia (ADH), and ductal carcinoma in situ (DCIS). Women with UDH have 2.5 times lower risk of subsequent cancer development as compared to those with $\mathrm{ADH}$, the later stage of UDH [3]. It is known that these lesions are in fact part of a progressive process, which shows continuity and the steps of which are not explicit. In breast cancer, which is a biologically heterogeneous disease with a clinical course that may vary from slow to rapid progression, immunohistochemical markers are needed to predict prognosis and metastatic disease and to overcome problems associated with differential diagnosis [4].

Cytokeratins are intracellular fibrous proteins found in almost all epithelial tissues. There exist at least 20 subtypes defined according to the molecular weight. High molecular weight cytokeratin (HMWCK), also known as $34 \beta E 12$, is specific to keratin in basilar cells [5]. Its expression is of benefit in the differential diagnosis of benign lesions such as UDH or ADH, which maintain basal differentiation character. Some researchers observed a decrease in the expression of HMWCK in the order of UDH, ADH and DCIS lesions and advocated that this marker could be useful in the differential diagnosis of intraductal proliferative lesions of the breast [5].

In cell cycle, p27 possesses a key role. It is known that apoptosis regulator Bcl-2 affects cell cycle progression by increasing p27 levels [6]. The decrease in the expression of $\mathrm{p} 27$ protein has been reported correlated with poor prognosis, disease recurrence, and disease-related deaths in patients with early-stage breast cancer, and decreased expression of p27 has been supported to be an independent indicator of poor prognosis [7]. In various studies, decreased p27 expression suggested being an important option for targeted therapy in cancer treatment [8].

The chemokines are small molecules from the chemo-attractive cytokine family. They are divided into four subgroups, according to their characteristic residual cysteine component, as $\alpha(\mathrm{C}-\mathrm{X}-\mathrm{C}), \beta(\mathrm{C}-\mathrm{C})$, $\gamma(\mathrm{C})$ and $\delta(\mathrm{C}-\mathrm{X}-\mathrm{X}-\mathrm{X}-\mathrm{C})$ [9]. SDF-1, or CXCL-12, is a member of chemokine $\alpha$ subgroup and is the sole ligand ever known of G-protein coupled chemokine receptor called CXCR-4 $[10,11]$. SDF-1 is produced in many organs including lungs, liver, bones, brain, thymus and lymph nodes, basically by the stromal cells [12]. Disruption in the SDF-1/CXCR-4 interaction negatively affects the development of hematopoietic, cardiovascular and neural systems, leading, in turn, to defective embryonic development [13].

In the present study, we aimed to evaluate the prognostic value of HMWCK, p27, CXCR-4 and SDF-1 markers in benign proliferative diseases, DCIS, and IDC immunohistochemically. As well as the utility of these markers in eliminating the problems associated with a differential diagnosis of these diseases and in tumor progression steps.

\section{METHODS}

\section{Case Selection}

A review of all modified radical mastectomy specimens, excisional breast biopsies, and needle core biopsies of the breast that evaluated between 2006 and 2008. The cases divided into the following two groups according to the presence of cancer: 1) cancer group (298 cases; cases with IDC and DCIS), 2) non-cancer group (67 cases without cancer; cases with UDH and $\mathrm{ADH})$. Among five hundred and thirty-five breast biopsies, three hundred and ninety-six cases with the diagnosis of UDH, ADH, DCIS, and IDC selected, and 365 cases which were suitable for tissue microarray, included in the study.

The ethical review committee of Gazi University Medical Faculty approved the study. The authors declare that they had all necessary consent from any patients involved in the study.

\section{Tissue Microarray and Preparation of Paraffin Blocks}

Tissue microarray (TMA) is a method that allows for analysis of multiple tissues from different patients or different blocks on the same slide by obtaining tissue cores fromconventional paraffin blocks [14]. During the examination of breast biopsies, we choose four representative microscopic fields of the lesion. We removed tissue cores from the marked fields in paraffin-embedded donor blocks using a $0.1-\mathrm{cm}$ needle (Veridiam advanced tissue arrayer, VTA-100, USA). We arrayed these tissue cores into a recipient TMA block. Accordingly, we constructed 22 TMA 
paraffin blocks each containing 20 different tissue cores (on average). Paraffin blocks were sectioned at $5 \mu \mathrm{m}$, and sections were then mounted on polylysinecoated slides.

\section{Immunohistochemical Staining and Evaluation}

Staining was performed using three-step indirect streptavidin-biotin immunoperoxidase method to determine HMWCK, p27, CXCR-4 and SDF-1 expression. HMWCK (Thermo Scientific, Mouse monoclonal IgG1, Runcorn. Cheshire, UK), p27 (Thermo Scientific p27 Kip1, Runcorn. Cheshire, UK), CXCR-4 (Santa Cruz, Fusin H-118, CA, USA) and SDF-1 (Santa Cruz, P-159X, CA, USA) antibodies were diluted 1:50 in phosphate buffered saline ( $\mathrm{pH} 7.4, \mathrm{PBS})$. Biotinylated secondary linking antibody, streptavidin-biotin complex, and the chromogens 3,3'-diaminobenzidine (DAB) and 3amino-9-ethylcarbazole (AEC) were available as ready-to-use commercial kits. Cytoplasmic staining for HMWCK, CXCR-4, SDF-1 and nuclear staining for $\mathrm{p} 27$ were considered positive in the evaluation of immunohistochemical staining. Normal skin, normal spleen and normal liver tissues used as a positive control for HMWCK, CXCR-4 and SDF-1 antibody, respectively, whereas prostaticadenocarcinoma and normal prostate tissue selected as positive controls for the p27 antibody. The staining intensity and extensity noted as percentages.

\section{Statistical Analysis}

Multi-group comparisons were performed using analysis of variance (ANOVA) for normally distributed numerical variables and the Kruskal-Wallis test for non-normally distributed variables. Paired comparisons were carried out using the Student's t-test for normally distributed numerical variables and the Mann-Whitney U test for non-normally distributed numerical variables. A p-value $<0.05$ was considered statistically significant. In subgroup analyses, the level of significance was evaluated with Bonferronicorrected $p$ values. The Statistical Package for Social Sciences (SPSS, Inc., Chicago, IL, USA) version 12 was used in statistical analyses.

\section{RESULTS}

Three hundred and sixty-five cases included in the study. IDC was present in 277 cases, of which 213 had pure IDC, and 64 had DCIS component adjacent to the invasive tumor. Twenty-one cases had DCIS. Of 67 cases with epithelial hyperplasia, 31 had ADH, and 36 had UDH. Of 298 cases with IDC and DCIS, 157 were mastectomies, and excisional biopsy specimens and 141 were needle biopsy specimens. Data on tumor diameter was available only for mastectomy or excisional biopsy specimens. Of 157 cases, tumor diameter was $\leq 2 \mathrm{~cm}$ in 80 cases and $>2 \mathrm{~cm}$ in 77 cases. Among cases with IDC, 143 cases had lymph node excision, of which 73 had metastasis in one or more lymph nodes, and 70 did not have metastatic disease.

The intensity of staining with HMWCK, p27, CXCR-4 and SDF-1 antibodies was 14\%, 10\%, 15\% and $23 \%$ in average in the UDH group, $20 \%, 18 \%$, $15 \%$ and $33 \%$ in the ADH group, $5 \%, 3 \%, 37 \%$ and $50 \%$ in the DCIS group, $5 \%, 4 \%, 34 \%$ and $33 \%$ in the IDC group without DCIS component, and $8 \%, 6 \%$, $43 \%$ and $34 \%$ in the IDC group with DCIS component
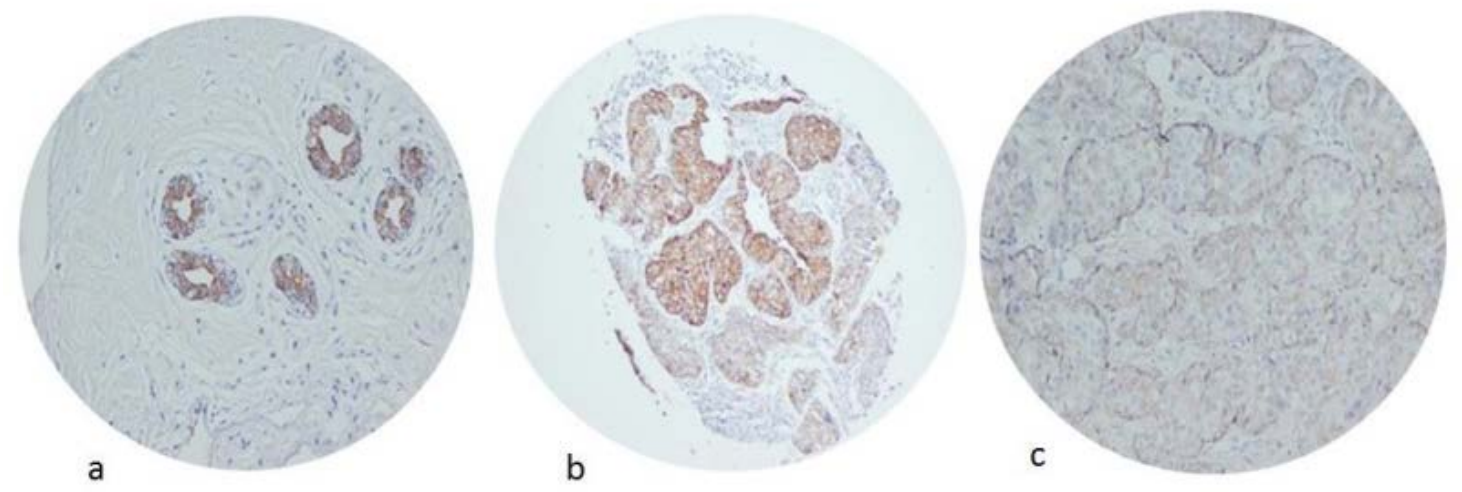

Figure 1. HMWCK expression was found to be higher in the UDH (a) and ADH (b) group than in the IDC (c) group. (a) HMWCK $\times 100$, (b) $\mathrm{HMWCK} \times 40$, and (c) $\mathrm{HMWCK} \times 100$. 
Table 1. Distribution of HMWCK, p27, CXCR-4 and SDF-1 expressions according to the cases

\begin{tabular}{|c|c|c|c|c|c|c|c|c|c|c|}
\hline & \multirow[t]{2}{*}{$\begin{array}{l}\text { No of } \\
\text { cases }\end{array}$} & \multicolumn{4}{|c|}{$\begin{array}{l}\text { Staining intensity } \\
\text { (mean of \%) }\end{array}$} & & \multicolumn{4}{|c|}{ p value } \\
\hline & & $\begin{array}{c}\text { HMW } \\
\text { CK }\end{array}$ & p27 & CXCR-4 & SDF-1 & & HMWCK & p27 & CXCR-4 & SDF-1 \\
\hline \multirow{4}{*}{ UDH } & \multirow{4}{*}{36} & \multirow{4}{*}{$14 \pm 19$} & \multirow{4}{*}{$10 \pm 17$} & \multirow{4}{*}{$15 \pm 23$} & \multirow{4}{*}{$23 \pm 28$} & ADH & 0.55 & 0.001 & 0.66 & 0.21 \\
\hline & & & & & & DCIS & 0.03 & 0.29 & 0.04 & 0.004 \\
\hline & & & & & & $\begin{array}{c}\text { IDC } \\
\text { (w/o } \\
\text { DCIS) }\end{array}$ & 0.0007 & 0.005 & 0.001 & 0.01 \\
\hline & & & & & & $\begin{array}{c}\text { IDC } \\
\text { (w/ DCIS) }\end{array}$ & 0.02 & 0.48 & 0.00001 & 0.07 \\
\hline \multirow{3}{*}{ ADH } & \multirow{3}{*}{31} & \multirow{3}{*}{$20 \pm 28$} & \multirow{3}{*}{$18 \pm 14$} & \multirow{3}{*}{$15 \pm 27$} & \multirow{3}{*}{$33 \pm 32$} & DCIS & 0.01 & 0.0001 & 0.04 & 0.06 \\
\hline & & & & & & $\begin{array}{c}\text { IDC } \\
\text { (w/o } \\
\text { DCIS) }\end{array}$ & 0.0001 & 0.0001 & 0.001 & 0.65 \\
\hline & & & & & & $\begin{array}{c}\text { IDC } \\
\text { (w/ DCIS) }\end{array}$ & 0.006 & 0.0001 & 0.00001 & 0.75 \\
\hline \multirow[t]{2}{*}{ DCIS } & \multirow[t]{2}{*}{21} & \multirow[t]{2}{*}{$5 \pm 11$} & \multirow[t]{2}{*}{$3 \pm 4$} & \multirow[t]{2}{*}{$37 \pm 39$} & \multirow[t]{2}{*}{$50 \pm 38$} & $\begin{array}{c}\text { IDC } \\
(w / 0 \\
\text { DCIS) }\end{array}$ & 0.91 & 0.13 & 0.91 & 0.06 \\
\hline & & & & & & $\begin{array}{c}\text { IDC } \\
\text { (w/ DCIS) }\end{array}$ & 0.66 & 0.66 & 0.40 & 0.12 \\
\hline $\begin{array}{l}\text { IDC } \\
\text { w/o DCIS }\end{array}$ & 213 & $5 \pm 15$ & $4 \pm 10$ & $34 \pm 34$ & $33 \pm 28$ & $\begin{array}{c}\text { IDC } \\
\text { (w/ DCIS) }\end{array}$ & & & & \\
\hline $\begin{array}{l}\text { IDC } \\
\text { w/ DCIS }\end{array}$ & 64 & $8 \pm 21$ & $6 \pm 11$ & $43 \pm 33$ & $34 \pm 32$ & $\begin{array}{c}\text { IDC } \\
\text { (w/o } \\
\text { DCIS) }\end{array}$ & 0.56 & 0.004 & 0.03 & 0.98 \\
\hline
\end{tabular}

HMWCK $=$ high molecular weight cytokeratin, CXCR-4 $=$ C-X-C chemokine receptor type 4, SDF-1 $=$ stromal cell-derived factor $1, \mathrm{UDH}=$ Usual ductal hyperplasia, $\mathrm{ADH}=$ Atypical ductal hyperplasia, DCIS = Ductal carcinoma in situ, IDC w/o DCIS = Invasive ductal carcinoma without DCIS, IDC w/ DCIS = Invasive ductal carcinoma with DCIS

Table 2. Distribution of HMWCK, p27, CXCR-4 and SDF-1 expressions according to other variables.

\begin{tabular}{|c|c|c|c|c|c|c|c|c|c|}
\hline & \multirow{2}{*}{$\begin{array}{l}\text { No of } \\
\text { cases }\end{array}$} & \multicolumn{4}{|c|}{ Staining intensity (\%) } & \multicolumn{4}{|c|}{ p value } \\
\hline & & HMWCK & p27 & CXCR-4 & SDF-1 & HMWCK & p27 & CXCR-4 & SDF-1 \\
\hline \multicolumn{10}{|c|}{ Presence of cancer } \\
\hline Cancer & 298 & $6 \pm 16$ & $4 \pm 10$ & $36 \pm 34$ & $34 \pm 30$ & \multirow{2}{*}{$<0.0001$} & \multirow{2}{*}{$<0.0001$} & \multirow{2}{*}{$<0.0001$} & \multirow{2}{*}{0.03} \\
\hline Benign & 67 & $17 \pm 24$ & $14 \pm 16$ & $15 \pm 25$ & $27 \pm 30$ & & & & \\
\hline \multicolumn{10}{|c|}{ Tumor diameter } \\
\hline $2 \mathrm{~cm} \downarrow$ & 80 & $7 \pm 18$ & $5 \pm 11$ & $34 \pm 34$ & $34 \pm 28$ & \multirow{2}{*}{0.14} & \multirow{2}{*}{0.16} & \multirow{2}{*}{0.10} & \multirow{2}{*}{0.45} \\
\hline $2 \mathrm{~cm} \uparrow$ & 77 & $6 \pm 18$ & $2 \pm 7$ & $42 \pm 31$ & $29 \pm 25$ & & & & \\
\hline \multicolumn{10}{|c|}{ Lymph node metastasis } \\
\hline Present & 73 & $6 \pm 16$ & $4 \pm 11$ & $39 \pm 33$ & $34 \pm 27$ & \multirow{2}{*}{0.93} & \multirow{2}{*}{0.07} & \multirow{2}{*}{0.61} & \multirow{2}{*}{0.23} \\
\hline None & 70 & $8 \pm 20$ & $4 \pm 8$ & $37 \pm 33$ & $30 \pm 28$ & & & & \\
\hline
\end{tabular}

HMWCK $=$ high molecular weight cytokeratin, CXCR-4 = C-X-C chemokine receptor type 4 , SDF-1 = stromal cellderived factor 1 

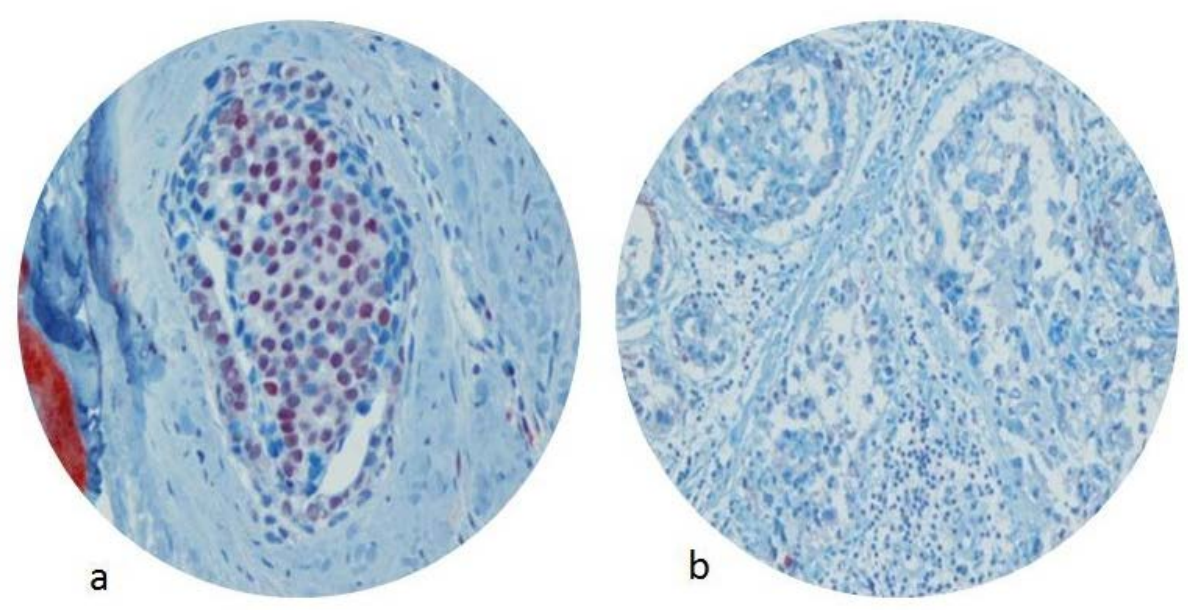

Figure 2. The expression of p27 was found to be significantly higher in the non-cancer group (a) as compared to that in the cancer group (b). (a) p27 $\times 200$ and (b) p27 $\times 200$.

(Table 1). Also, HMWCK, p27, CXCR-4 and SDF-1 expressions compared with the presence of cancer, lymph node metastasis status and tumor diameter (Table 2).

In the present study, there was no significant difference between the UDH and ADH groups regarding HMWCK expression; however, both epithelial hyperplasia groups exhibited significantly higher staining intensity as compared to the IDC group $(p<0.005$ for each) (Figure 1). The expression of $\mathrm{p} 27$ was found to be significantly lower in the cancer group as compared to that in the non-cancer group ( $p<$ 0.0001) (Figure 2). Furthermore, p27 expression was significantly higher in the ADH group when compared individually to the IDC and DCIS groups $(p<0.0001)$ for each. When the epithelial hyperplasia groups compared, p27 expression found higher in the ADH group than that in the UDH group. We could not find a significant association between tumor size and
HMWCK or $\mathrm{p} 27$ expression or between the presence of metastatic disease and HMWCK or p27 expression.

After DCIS step, CXCR-4 receptor expression increased markedly $(p<0.001)$ through carcinogenesis. CXCR-4 expression in IDC was found to be higher than that of DCIS group (Figure 3). Although it wasn't statistically significant, a directly proportional increment between CXCR-4 expression and the presence of lymph node metastasis and the increase in tumor diameter was detected. SDF-1 expression was observed to be significantly higher in cancer cases than that of non-cancer cases $(p=0.03)$ (Figure 4). It is remarkable that each group in the cancer cases showed more SDF-1 expression than $\mathrm{ADH}$ and UDH groups. In epithelial hyperplasia group, SDF-1 expression was found to be higher in ADH group than UDH group. Also, SDF-1 expression was also higher in tumors with lymph node metastasis.

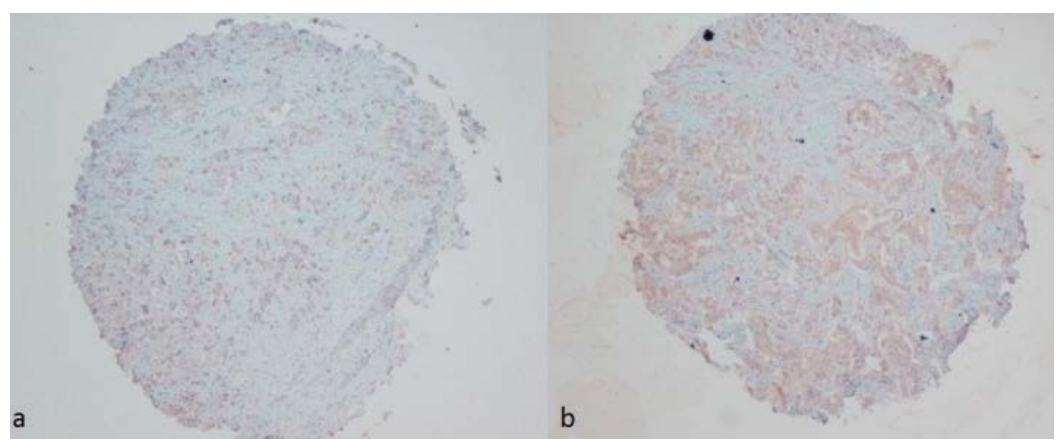

Figure 3. Comparison between the ADH (a) and IDC (b), CXCR-4 receptor expression increased markedly after DCIS step, through carcinogenesis [CXCR-4 stain (a) $\times 40$, (b) $\times 40$ ]. 


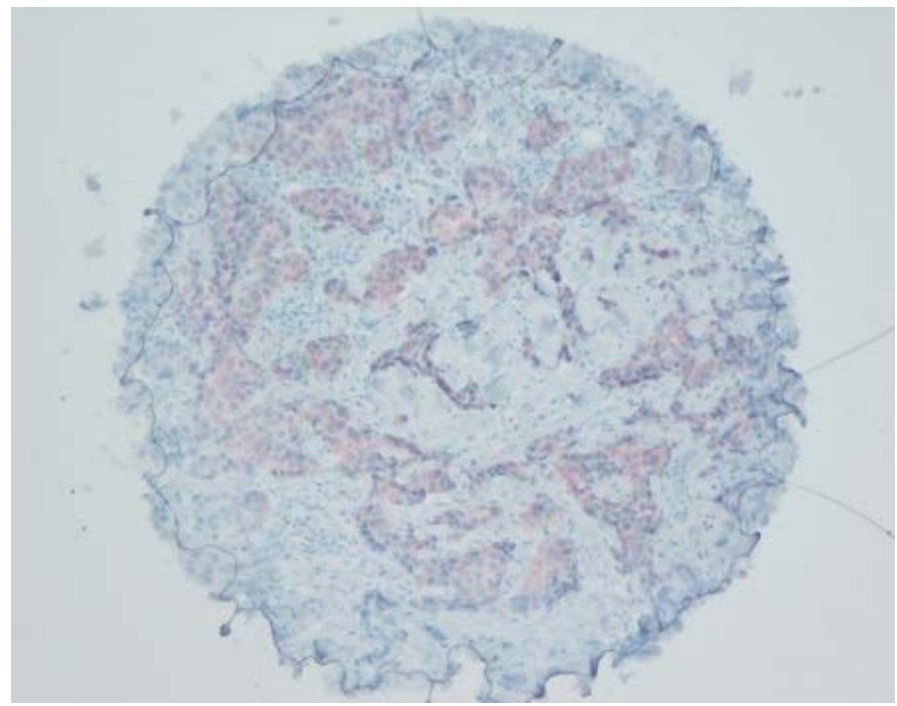

Figure 4. SDF-1 expression was observed to be significantly higher in cancer cases $($ SDF-1 stain $\times 40)$

\section{DISCUSSION}

Breast cancer is a biologically heterogeneous disease. Clinical parameters associated with prognoses such as tumor size and lymph node status are utilized [15]; however, there is still research on markers that could predict clinical course in patients with negative lymph nodes.

In the carcinogenesis of breast cancer, it is known that ADH progress to DCIS with an increase in atypia and eventually to invasive carcinoma [16]. It has been demonstrated that cases with DCIS have chromosomal instability similar to those with IDC and low/moderate- and high-grade DCIS have different small chromosomal changes [17]. Transition across these steps may not be explicit. Differentiation between ADH and DCIS or between DCIS and IDC can be challenging [18]. Immunohistochemical markers could be helpful in such diagnostic challenges. The HMWCK expression is of benefit in the differential diagnosis of benign lesions such as $\mathrm{UDH}$ or ADH. It has been stated that HMWCK is helpful in determining intraductal proliferative lesions and could be a supportive finding in the presence of atypia [19]. Some researchers observed a decrease in the expression of HMWCK in the order of UDH, ADH and DCIS lesions and advocated that this marker could be useful in the differential diagnosis of intraductal proliferative lesions of the breast [5].

In another study, diffuse and intense staining for
HMWCK was demonstrated in UDH and ADH areas, loss of staining or focal and weak expression was determined in DCIS cases; in the light of these findings, the authors regarded HMWCK as a helpful marker in problematic cases [20].

In this study, both epithelial hyperplasia groups exhibited significantly higher HMWCK staining intensity as compared to the IDC group. This finding suggested that HMWCK expression might have been upregulated in benign proliferative lesions of the breast and down-regulated in the course ofthe progressive disease. As HMWCK expression was found to be higher in the ADH group than in the DCIS group, we thought that HMWCK expression could be beneficial in diagnosing cases who fall into a transitional zone in tumorigenesis and who, therefore, could represent diagnostic challenges.

In various studies, the decreased p27 expression has been accepted as the fundamental finding in breast cancer,and suggested to be an important option for targeted therapy in cancer treatment [8]. Moreover, it has been considered that increased p27 expression could be evaluated as an independent indicator of the prognosis $[15,21]$. The decrease in the expression of p27 protein has been reported to be correlated with poor prognosis, disease recurrence, and disease-related deaths in patients with early-stage breast cancer, and decreased expression of p27 has been supported to be an independent indicator of poor prognosis [7].

When the epithelial hyperplasia groups were compared, p27 expression was higher in the ADH group than that in the UDH group; this could be due to the lower number of cases with epithelial hyperplasia. The expression of p27 was found to be significantly lower in the cancer group as compared to that in the non-cancer group. p27 expression was significantly higher in the ADH group when compared individually to the IDC and DISC groups. These findings suggested that $\mathrm{p} 27$ expression disappeared with the development of cancer.

CXCR-4 was documented to play a role in the process of metastasis of numerous types of tumors [22], in organ-specific tumor extension stages [23]; in the induction of proliferation of tumor cells [24]; in the processes of invasion [25], and in neoangiogenesis [26]. Although CXCR-4 cannot be shown in the epithelium lining normal breast ducts, it 
commences being expressed after ADH step, representing a quite earlier step of malignant transformation [27].

In our study, after DCIS step, CXCR-4 receptor expression increased markedly through carcinogenesis. CXCR-4 expression in IDC was found to be higher than that of DCIS group. It was documented to reveal an increase in CXCR-4 expression with the progression through the steps of tumor generation. SDF-1 expression was observed to be significantly higher in cancer cases than that of non-cancer cases. Also, in epithelial hyperplasia group, SDF-1 expression was found to be higher in ADH group than UDH group. These results suggest that SDF-1 expression can be used as one of the poor prognostic markers.

The presence of metastasis has proven to be one of the most important prognostic factors determining life expectancy for breast cancer patients. The axillary lymph nodes are the most commonly encountered metastasis site in patients with invasive breast cancer, occurring in 38\% of these cases [28]. The CXCR-4 receptor was also reported to be expressed in the anatomic regions to which distinct types of cancerous tumors spread, and this observation was considered to be in favor of the theory regarding organ-specific attracting molecules in the process of migration of tumor cells to specific regions [29]. Genetic investigations suggested that the interaction between SDF-1 and CXCR-4 was associated with the aggressive course, increased invasion potential and rapid tumor growth [30]. Moreover, it has been advocated that the breast cancer cases possessing SDF-1/CXCR-4 complexes were more invasive and more rapidly migrating and that SDF-1 level was useful in predicting lymph node involvement, recurrences and disease-free survival time [31].

SDF-1 has been expressed very intensely aroundcancer and in the lymph nodes draining the cancerous area [32]. In addition to metastatic axillary lymph nodes, high levels of CXCR-4 expression was also reported in the metastatic breast carcinomas to the liver and the lungs [33]. A significant correlation has been detected between diffuse nuclear CXCR-4 positivity and lymph node metastasis [34].

In our study, a directly proportional increment between CXCR-4 expression and the presence of lymph node metastasis and the increase in tumor diameter was detected. SDF-1 expression was also higher in tumors with lymph node metastasis. Thus prompting us to consider that CXCR-4 and SDF-1 might be used as an ominous prognostic indicator in general tumor pathogenesis steps.

\section{CONCLUSION}

Breast carcinoma is one of the tumors of which early diagnosis and treatment are of vital importance. Researches have resulted in an array of immunohistochemical markers that would have prognostic value in tissues accessible by needle biopsy, which is relatively an easy method. In the present study, we found that HMWCK and p27 were expressed in the non-cancer group and when used together, they could be beneficial in biopsies particularly in cases with ADH and DCIS where the lesions lie in the transitional zone and represent a challenge in the differential diagnosis. We concluded that the indicators, CXCR-4 and SDF-1, could be used as poor prognostic factors compatible with an increase in tumor diameter and the presence of lymph node metastasis during the steps of tumorigenesis.

\section{Authors 'Contributions}

$\mathrm{GO}=$ designed and performed the research analyzed the data and wrote the manuscript. GA = analyzed the data and designed the research. All authors read and approved the final manuscript.

\section{Conflict of interest}

The author disclosed no conflict of interest during the preparation or publication of this manuscript.

\section{Acknowledgments}

This work is supported by Gazi University Scientific Research Projects Unit (project number SBE-01/2007-104).

\section{REFERENCES}

[1] Rosai J. Rosai and Ackerman's Surgical Pathology, Vol. 2, 9th ed., Mosby: London, 2004. 
[2] Rosen PP. Rosen's Breast Pathology. Lippincott Williams\&Wilking: Philadelphia, 2008.

[3] Mills SE. Sternberg's Diagnostic Surgical Pathology, Vol. 1, 4th ed., Lippincott Williams\&Wilkins: Philadelphia, 2004.

[4] Dabbs D. Diagnostic Immunohistochemistry. Churchill Livingstone Elsevier: USA, 2006, 699-746 pp.

[5] Zhang JL, Zhang HY, Wei B, Lang ZQ, Bu H. [Role of cytokeratin expression in differential diagnosis of intraductal proliferative lesions of breast]. Zhonghua Bing Li Xue Za Zhi 2004;33:316-9. [Article in Chinese]

[6] Bonnefoy-Berard N, Aouacheria A, Verschelde C, Qemeneur L, Marçais A, Marvel J. Control of proliferation by Bcl-2 family members. Biochim Biophys Acta 2004;1644:159-68.

[7] Catzavelos C, Bhattacharya N, Ung YC, Wilson JA, Roncari L, Sandhu C, et al. Decreased levels of the cell-cycle inhibitor p27Kip1 protein: prognostic implications in primary breast cancer. Nat Med 1997;3: 227-30.

[8] Traub F, Mengel M, Luck HJ, Kreipe HH, von Wasielewski R. Prognostic impact of Skp2 and p27 in human breast cancer. Breast Cancer Res Treat 2006;99:185-91.

[9] Luster AD. Chemokines--chemotactic cytokines that mediate inflammation. N Engl J Med 1998;338:436-45.

[10] Hamada T, Tashiro K, Tada H, Inazawa J, Shirozu M, Shibahara $\mathrm{K}$, et al. Isolation and characterization of a novel secretory protein, stromal cell-derived factor-2 (SDF-2) using the signal sequence trap method. Gene 1996;176: 211-4.

[11] Zlotnik A, Yoshie O. Chemokines: a new classification system and their role in immunity. Immunity 2000;12:121-7.

[12] Shirozu M, Nakano T, Inazawa J, Tashiro K, Tada H, Shinohara T, et al. Structure and chromosomal localization of the human stromal cell-derived factor 1 (SDF1) gene. Genomics 1995;28:495-500.

[13] Ma Q, Jones D, Borghesani PR, Segal RA, Nagasawa T, Kishimoto T, et al. Impaired B-lymphopoiesis, myelopoiesis, and derailed cerebellar neuron migration in CXCR4- and SDF-1deficient mice. Proc Natl Acad Sci U S A 1998;95:9448-53.

[14] Wan WH, Fortuna MB, Furmanski P. A rapid and efficient method for testing immunohistochemical reactivity of monoclonal antibodies against multiple tissue samples simultaneously. J Immunol Methods 1987;103:121-9.

[15] Wu J, Shen ZZ, Lu JS, Jiang M, Han QX, Fontana JA, et al. Prognostic role of $\mathrm{p} 27 \mathrm{Kip} 1$ and apoptosis in human breast cancer. Br J Cancer 1999;79:1572-8.

[16] Marlow R, Strickland P, Lee JS, Wu X, Pebenito M, Binnewies $M$, et al. SLITs suppress tumor growth in vivo by silencing Sdf1/Cxcr4 within breast epithelium. Cancer Res 2008;68:7819-27.

[17] Hwang ES, DeVries S, Chew KL, Moore DH 2nd, Kerliowske T, Thor A, et al. Patterns of chromosomal alterations in breast ductal carcinoma in situ. Clin Cancer Res 2004;10:51607.

[18] Sakorafas GH, Tsiotou AG. Ductal carcinoma in situ (DCIS) of the breast: evolving perspectives. Cancer Treat Rev 2000;26:103-25.

[19] Gal-Gombos EC, Esserman LE, Recine MA, Poppiti RJ, Jr.
Large-needle core biopsy in atypical intraductal epithelial hyperplasia including immunohistochemical expression of high molecular weight cytokeratin: analysis of results of a single institution. Breast J 2002;8:269-74.

[20] Moinfar F, Man YG, Lininger RA, Bodian C, Tavassoli FA. Use of keratin 35betaE12 as an adjunct in the diagnosis of mammary intraepithelial neoplasia-ductal type--benign and malignant intraductal proliferations. Am J Surg Pathol 1999;23:1048-58.

[21] Tan P, Cady B, Wanner M, Worland P, Cukor B, MagiGalluzzi C, et al. The cell cycle inhibitor p27 is an independent prognostic marker in small $(\mathrm{T} 1 \mathrm{a}, \mathrm{b})$ invasive breast carcinomas. Cancer Res 1997;57:1259-63.

[22] Dorsam RT, Gutkind JS. G-protein-coupled receptors and cancer. Nat Rev Cancer 2007;7:79-94.

[23] Cabioglu N, Yazici MS, Arun B, Broglio KR, Hortobagyi GN, Price JE, et al. CCR7 and CXCR4 as novel biomarkers predicting axillary lymph node metastasis in $\mathrm{T} 1$ breast cancer. Clin Cancer Res 2005;11:5686-93.

[24] Yoon Y, Liang Z, Zhang X, Choe M, Zhu A, Cho HT, et al. CXC chemokine receptor-4 antagonist blocks both growth of primary tumor and metastasis of head and neck cancer in xenograft mouse models. Cancer Res 2007;67:7518-24.

[25] Chinni SR, Sivalogan S, Dong Z, Filho JC, Deng X, Bonfil RD, et al. CXCL12/CXCR4 signaling activates Akt-1 and MMP9 expression in prostate cancer cells: the role of bone microenvironment-associated CXCL12. Prostate 2006;66:32-48. [26] Wang J, Sun Y, Song W, Nor JE, Wang CY, Taichman RS. Diverse signaling pathways through the SDF-1/CXCR4 chemokine axis in prostate cancer cell lines leads to altered patterns of cytokine secretion and angiogenesis. Cell Signal 2005; 17:1578-92.

[27] Schmid BC, Rudas M, Rezniczek GA, Leodolter S, Zeillinger R. CXCR4 is expressed in ductal carcinoma in situ of the breast and in atypical ductal hyperplasia. Breast Cancer Res Treat 2004;84:247-50.

[28] Silverstein MJ, Skinner KA, Lomis TJ. Predicting axillary nodal positivity in 2282 patients with breast carcinoma. World J Surg 2001;25:767-72.

[29] Liotta LA. An attractive force in metastasis. Nature 2001;410:24-5.

[30] Kang H, Mansel RE, Jiang WG. Genetic manipulation of stromal cell-derived factor- 1 attests the pivotal role of the autocrine SDF-1-CXCR4 pathway in the aggressiveness of breast cancer cells. Int J Oncol 2005;26:1429-34.

[31] Kang H, Watkins G, Parr C, Douglas-Jones A, Mensel RE, Jiang WG. Stromal cell derived factor-1: its influence on invasiveness and migration of breast cancer cells in vitro, and its association with prognosis and survival in human breast cancer. Breast Cancer Res 2005;7: R402-10.

[32] Müller A, Homey B, Soto H, Ge N, Catron D, Buchanan $\mathrm{ME}$, et al. Involvement of chemokine receptors in breast cancer metastasis. Nature 2001;410:50-6.

[33] Chen Y, Stamatoyannopoulos G, Song CZ. Down-regulation of CXCR4 by inducible small interfering RNA inhibits breast 
cancer cell invasion in vitro. Cancer Res 2003;63:4801-4.

[34] Woo SU, Bae JW, Kim CH, Lee JB, Koo BW. A significant correlation between nuclear CXCR4 expression and axillary lymph node metastasis in hormonal receptor negative breast cancer. Ann Surg Oncol 2008;15:281-5. 